\title{
Comportamento social do pirá-brasília, Simpsonichthys boitonei Carvalho (Cyprinodontiformes, Rivulidae)
}

\author{
Oscar A. Shibatta \\ Museu de Zoologia, Departamento de Biologia Animal e Vegetal, Centro de Ciências Biológicas, Universidade Estadual de \\ Londrina.86051-970 Londrina, Paraná, Brasil. E-mail: shibatta@uel.br
}

\begin{abstract}
Social behavior of pirá-brasília, Simpsonichthys boitonei Carvalho (Cyprinodontiformes, Rivulidae). The social behavior of pirá-brasília, Simpsonichthys boitonei Carvalho, 1959, can be divided in two groups: the reproductive and the agonistic. In reproductive behavior was observed that the male courts the female when she approaches, through the vibration of body and change in the color pattern, from red to dark blue. The male drives the female until substratum, where they penetrate and accomplish the spawn after lateral compression of the male's body on the female. The ritual of spawn repeats several times until the female leaves. The agonistic behavior is more frequent among males, but can happen occasionally between males and females and within females. The behavior patterns of menace are: extension of fins, caudal-fin open and close, increase in pectoralfin movements, operculum expansion and red coloration increasing. After the exhibition of these patterns can happen attack or escape. In many times escape happens without apparent opponent threatens or attack, but for the opponent's simple presence. The males are territorial, defending the permanence place - with preference of inferior area of water column - that is still used for food search and for reproduction. Dominance happens among males and also among females. Elaborated behaviors of court and territory can be important for those animals that live in temporary pools, whose physical and chemical characteristics can be not very stable. KEY WORDS. Aggressive behavior; annual fishes; reproduction; territory.
\end{abstract}

RESUMO. O comportamento social do pirá-brasília, Simpsonichthys boitonei Carvalho, 1959, pode ser dividido em dois grupos: o reprodutivo e o agonístico. No comportamento reprodutivo observou-se que o macho corteja a fêmea quando ela se aproxima, através do estremecimento do corpo e mudança no padrão de colorido, de vermelho para azul escuro. O macho conduz a fêmea até o substrato, onde se enterram e realizam a desova após compressão lateral do corpo do macho sobre a fêmea. $\mathrm{O}$ ritual de desova repete-se várias vezes até que a fêmea se afaste. $\mathrm{O}$ comportamento agonístico é mais freqüente entre machos, mas pode ocorrer ocasionalmente entre machos e fêmeas e entre fêmeas. Os padrões comportamentais que caracterizam ameaça são: extensão das nadadeiras, abrir e fechar da nadadeira caudal, aumento dos movimentos das nadadeiras peitorais, expansão do opérculo e intensificação da coloração avermelhada. Após a exibição desses padrões pode ocorrer o ataque ou a fuga. Muitas vezes a fuga ocorre sem que haja ameaça ou ataque aparente, e sim pela simples presença do oponente. Os machos são territorialistas, defendendo o local de permanência - preferencialmente a região inferior da coluna da água - que ainda é utilizado para busca de alimento e para a reprodução. Ocorre dominância entre machos e entre fêmeas. Comportamentos elaborados de corte e territorialidade podem ser importantes para esses animais que vivem em poças temporárias, cujas características físicas e químicas podem ser pouco estáveis.

PALAVRAS-CHAVE. Comportamento agressivo; peixes anuais; reprodução; territorialidade.

O pirá-brasília, Simpsonichthys boitonei Carvalho, 1959, vive em pequenas poças temporárias sendo classificado como peixe-anual (Costa 2002). Foi descrito a partir de uma amostra coletada no Jardim Zoológico de Brasília por CARvalHo (1959), onde provavelmente encontra-se extinto. Atualmente, uma população está protegida na Reserva Ecológica do Instituto Brasileiro de Geografia e Estatística (RECOR), região sul do Distri- to Federal, no Brejo da Cerca, próximo ao ribeirão Taquara, afluente do ribeirão do Gama (Shibatta \& Garavello 1992).

A espécie apresenta acentuado dimorfismo sexual, tendo o macho, nadadeiras dorsal e anal com as extremidades pontiagudas, lateral do corpo vermelho-escura com faixas azul-metálicas na região anterior e séries verticais de pintas da mesma cor na região posterior. Nadadeiras dorsal e anal vermelho-es- 
curas, com pintas azuis na base e uma faixa horizontal mediana azul. Nadadeira dorsal podendo, também, apresentar uma mancha negra na região basal. Nadadeira caudal levemente avermelhada com manchas e margens azuladas. Quatro faixas avermelhadas nas laterais da cabeça: a primeira cruzando os olhos, a segunda próxima à margem posterior da órbita e duas na região opercular. O colorido da fêmea é castanho claro, com faixas verticais mais escuras, uma a três manchas negras no meio do corpo e nadadeiras hialinas. Detalhes das características morfológicas e fotos coloridas de machos e fêmeas podem ser observados em Costa $(1995,2002)$.

Algumas revistas especializadas em aquariofilia já publicaram artigos sobre o comportamento de $S$. boitonei, principalmente sobre seus hábitos de vida e reprodução (Peters \& SEEgERs 1978, Kadlec 1986, Couture 1988, 1989). Entretanto, nenhum trabalho apresentou ainda uma descrição detalhada desses comportamentos. Uma análise mais abrangente do comportamento reprodutivo em Simpsonichthys Carvalho, 1959 foi apresentada por Belote \& Costa (2002).

Este estudo objetivou descrever o comportamento de $S$. boitonei em cativeiro, relacionado às interações sociais, identificados pelas atividades reprodutivas e agonísticas. Considerou-se como comportamento social, a interação de dois ou mais indivíduos, ou a influência de um indivíduo sobre o outro da mesma espécie (Dathier \& Stellar 1973, Manning 1977).

\section{MATERIAL E MÉTODOS}

Os exemplares de $S$. boitonei foram coletados na RECOR

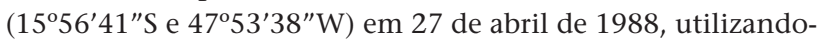
se peneiras grandes para arroz, com malhas de $1 \mathrm{~mm}$ entre nós adjacentes, e transportados até o laboratório em sacos plásticos com a água do local de coleta. Exemplares testemunhos da espécie estão depositados no Museu de Zoologia da Universidade Estadual de Londrina, Paraná.

As observações comportamentais foram feitas nos dias $14,15,17,20,21,22,24,27,28,30$ e 31 de junho de 1988 . Quatro machos - M1 (CP = 24,15 mm), M2 (CP = 23,15 mm), M3 $(\mathrm{CP}=21,10 \mathrm{~mm})$ e M4 $(\mathrm{CP}=19,15 \mathrm{~mm})$ - e três fêmeas $-\mathrm{F} 1$ $(\mathrm{CP}=21,30 \mathrm{~mm}), \mathrm{F} 2(\mathrm{CP}=21,75 \mathrm{~mm}), \mathrm{F} 3(\mathrm{CP}=22,40 \mathrm{~mm})-$ foram mantidos em um aquário de $144 \mathrm{~L}$ de capacidade $(80 \mathrm{~cm}$ de comprimento, 31 de largura e 58 de altura), preenchido com água de torneira. O substrato era constituído de turfa proveniente do local de coleta dos peixes, cascalho e filtro de fundo acionado por aerador. Em relação às paredes do aquário, apenas a frente não foi coberta com cartolina azul, para que os peixes pudessem ser observados. A luz era ligada diariamente às $8 \mathrm{~h}$ e desligada às $18 \mathrm{~h}$, quando o aquário era fechado frontalmente e superiormente para que ficasse completamente escuro. Os peixes foram alimentados com ração para peixes ornamentais às 8:00 e às 14:00 h. Antes do início das anotações dos padrões comportamentais esperava-se pelo menos 15 minutos, para que os peixes se habituassem com a presença do observador. Vinte e seis observações foram feitas através do método de

Revista Brasileira de Zoologia 23 (2): 375-380, junho 2006 amostragem ad libitum (AlTMANn 1974), totalizando 16h e 25min de observação. Deste total, foram utilizadas seis horas para a quantificação das interações sociais, nos horários de 8:30-9:00 h ( $\mathrm{n}=3$ sessões de observação), 9:00-9:30 h $(\mathrm{n}=2), 11: 00-11: 30 \mathrm{~h}$ $(\mathrm{n}=4), 16: 00-16: 30 \mathrm{~h}(\mathrm{n}=3)$. As observações das posições na coluna da água e da distribuição longitudinal e transversal foram feitas com o método de amostragem de varredura (scan), em oito sessões de duas horas (quatro entre 9:00-11:00 h e quatro entre 14:00-16:00 h), divididas em períodos de cinco minutos de observação, com intervalos de cinco minutos (12 amostras por sessão). A temperatura foi monitorada durante todo o experimento. A análise da similaridade na ocupação do espaço físico pelos exemplares foi feita utilizando-se o programa PAST (Hammer et al. 2001), com pares de coeficientes de similaridade de Bray-Curtis agrupados pelo método UPGMA.

\section{RESULTADOS}

Em seis horas de observações, ocorreram 787 interações sociais, sendo 295 (37,5\%) agonísticas entre machos, 82 (10,4\%) agonísticas entre fêmeas, 42 (5,3\%) agonísticas entre fêmeas e machos e 368 (46,8\%) reprodutivas entre machos e fêmeas. Destas, 12 interações resultaram em desovas nos horários $6: 30 \mathrm{~h}$, 8:30h, 9:30h, 10:30h, 10:51h, 10:57h, 11:00, 11:02, 12:30h e $16: 30 \mathrm{~h}$, evidenciando maior freqüência de desovas no período da manhã, mas com possibilidades de ocorrerem durante todo o período de atividades. A temperatura da água do aquário variou de 20 a $24^{\circ} \mathrm{C}(\mathrm{n}=8$, média $=23,25 \pm 1,39)$, com observações de desovas a 23 e $24^{\circ} \mathrm{C}$.

A quantificação das interações sociais dos machos e das fêmeas pode ser observada na tabela I, onde se verifica que M1 e M2 apresentaram a maior freqüência de interações, sendo os mais combativos. As poucas interações que M3 apresentou foram mais freqüentes com M4. Este, por sua vez, interagiu apenas uma vez com F2. Pelo número de interações é possível notar que existe uma ordem de dominância entre machos na seqüência decrescente: M1, M2, M3 e M4. O M2 foi o que mais interagiu com F2, embora F3 tenha sido abordada eqüitativamente pelos M1 e M2. Entre as fêmeas, F3 foi a que apresentou maior interação com outros indivíduos, principalmente com F2 (Tab. I).

Tabela I. Freqüência numérica de interações sociais entre machos (M) e fêmeas (F) de Simpsonichthys boitonei. Iniciativas das interações sociais sempre entre os indivíduos das linhas com os das colunas.

\begin{tabular}{ccccccrrr}
\hline Indivíduos & $\mathrm{M} 1$ & $\mathrm{M} 2$ & $\mathrm{M} 3$ & $\mathrm{M} 4$ & $\mathrm{~F} 1$ & $\mathrm{~F} 2$ & $\mathrm{~F} 3$ & Total \\
\hline M1 & - & 18 & 147 & 19 & 22 & 51 & 64 & 321 \\
M2 & 11 & - & 68 & 20 & 26 & 125 & 66 & 316 \\
M3 & 0 & 2 & \multicolumn{1}{c}{-} & 10 & 2 & 4 & 7 & 25 \\
M4 & 0 & 0 & 0 & - & & 1 & 0 & 1 \\
F1 & 0 & 0 & 0 & 0 & - & 4 & 2 & 6 \\
F2 & 0 & 0 & 2 & 0 & 1 & - & 1 & 4 \\
F3 & 5 & 10 & 22 & 3 & 11 & 63 & - & 114 \\
\hline
\end{tabular}




\section{Comportamento agonístico}

Nas relações agonísticas entre machos ocorrem ataques, ameaças e fugas. Freqüentemente um indivíduo foge pela simples presença do adversário, sem que ocorra ameaça ou ataque aparente. As esquivas (fugas precedidas por ameaças) também foram observadas. A ameaça é constituída por uma combinação de apresentações comportamentais descritas a seguir.

Assim que outro indivíduo é detectado, o opressor aproxima-se rapidamente, pára em frente ao oponente e exibe a lateral do corpo em posição horizontal ou vertical de cabeça para cima, com as nadadeiras dorsal e anal eretas. As membranas dessas nadadeiras ficam completamente estendidas em decorrência da ereção dos raios, evidenciando as manchas negras e as pintas iridescentes. A nadadeira caudal movimenta-se ritmicamente abrindo e fechando. As nadadeiras peitorais agitam-se com movimentos alternados para frente e para trás e mais rápido que na natação regular, não havendo, necessariamente, o deslocamento do corpo. De frente ao oponente, abre a boca, expande o opérculo e as membranas branquiostegais. O corpo se curva em forma sigmoidal antes do ataque.

Para o ataque, o opressor avança em direção ao oponente, desferindo-lhe uma mordida na região lateral do corpo ou nas nadadeiras. Os combates podem trazer como conseqüência a dilaceração das nadadeiras e perdas de escamas pelas mordidas. Podem ocorrer sucessivos ataques ao oponente, que foge ou que revida o ataque. É possível que o opressor ainda persiga o oponente após o ataque, o qual pode nadar em direção à superfície ou descer, enterrando-se no substrato. Esta última estratégia também é utilizada quando em presença de um possível predador (os movimentos bruscos do observador já eram suficientes para desencadear esse comportamento). Entretanto, enterrar-se no substrato nem sempre é utilizado para fuga, mas também para procura de alimento e desova. O exemplar macho vencido pode apresentar uma cor empalidecida.

No comportamento agonístico ocorre aumento da intensidade da cor vermelha e do azul iridescente das pintas das nadadeiras peitorais e caudal dos machos, ou aumento da intensidade da cor das faixas do corpo das fêmeas.

Com a aproximação da fêmea, o macho pode demonstrar comportamento de ameaça que finaliza em ataque ou corte. Fêmeas maiores que machos podem atacá-los. O comportamento agonístico entre fêmeas também ocorre, porém com menos freqüência, e segue os mesmos passos apresentados pelos machos. Como pode ser observado na tabela I, F3 apresen- tou dominância sobre F2 e F1 que, por sua vez, foi hierarquicamente superior a F2. Essas interações entre fêmeas ocorriam em diferentes momentos, não estando relacionadas a um determinado período do dia.

\section{Territorialidade}

Logo após os peixes serem soltos no aquário, os espaços foram ocupados aleatoriamente. À medida que ocorriam confrontos, os machos vencedores se estabeleciam em determinados locais próximos ao substrato e passavam a defendê-lo. Aqueles sem território tomavam uma parte do espaço do outro, através de ameaças e combates. Também foi observada pouca sobreposição de territórios, cuja defesa geralmente ocorreu com a invasão de outro macho em momentos de alimentação ou de cortejo de fêmeas. Estas, por sua vez, não defenderam o território e utilizavam a maior parte do tempo forrageando ou em outra atividade não social.

Inicialmente, no grupo, ocorreram dois machos dominantes (M1 e M2), sendo que M1 defendia um território que atingia uma área de cerca de $60 \%$ do aquário. Após 5 dias de observações, em decorrência de um possível problema de saúde do M1 (exemplar de maior tamanho), seu território diminuiu até inverter a proporção com outro macho dominante (M2), permanecendo assim até o final do experimento, mesmo com a rápida recuperação de $\mathrm{M} 1$.

Ressalta-se que os machos ocuparam os estratos da coluna da água de maneira distinta (Tab. II). M1 e M2 foram observados principalmente nos estratos médio e inferior, com maior tendência ao estrato inferior; M3 ocupou indistintamente todos os estratos e M4 manteve-se quase que completamente no estrato inferior, muitas vezes dentro do substrato. Analisando o número de interações deste macho com outros indivíduos (Tab. I) é possível notar que esta estratégia serviu para evitar confrontos, mas ao mesmo tempo impediu que ele interagisse com as fêmeas.Apesar da maior freqüência de fêmeas no estrato inferior da coluna da água, elas podem explorar os estratos superior (como F1, com 28,4\% de ocorrência) e médio (como F2, com 32,4\%).

Na tabela III pode-se observar que M1 ocupou principalmente um dos extremos do aquário (entre 60 e $80 \mathrm{~cm}$ ) enquanto M2 ocupou o outro (entre os espaços de 10 a $50 \mathrm{~cm}$ ), não tendo sido observado no espaço de $60 \mathrm{~cm}$, limite do território do M1. O M3 não apresentou território, embora tenha sido observado mais freqüentemente no limite do território do M1. O M4, por sua vez foi observado entre os territórios dos M1 e

Tabela II. Freqüência numérica e porcentual (entre parênteses) da posição de machos (M) e fêmeas (F) de Simpsonichthys boitonei em três estratos da coluna da água (observações em cativeiro).

\begin{tabular}{lccccccrrr}
\hline \multicolumn{1}{c}{ Estratos } & $\mathrm{M} 1$ & $\mathrm{M} 2$ & $\mathrm{M} 3$ & $\mathrm{M} 4$ & $\mathrm{~F} 1$ & $\mathrm{~F} 2$ & $\mathrm{~F} 3$ & Total \\
\hline Superior & 0 & $10(13,9)$ & $22(33,3)$ & 0 & $21(28,4)$ & 3 & $(4,2)$ & $9(12,5)$ & $65(14,2)$ \\
Médio & $10(14,7)$ & $19(26,4)$ & $22(33,3)$ & $3(9,7)$ & $15(20,3)$ & $23(32,4)$ & $14(19,4)$ & $106(23,1)$ \\
Inferior & $58(85,3)$ & $43(59,7)$ & $22(33,3)$ & $28(90,3)$ & $38(51,4)$ & $45(63,4)$ & $49(68,0)$ & $288(62,7)$ \\
\hline
\end{tabular}


Tabela III. Freqüência numérica e porcentual (entre parênteses) da distribuição longitudinal (em quadrantes de $10 \mathrm{~cm}$ de largura) de machos (M) e fêmeas (F) de Simpsonichthys boitonei em cativeiro.

\begin{tabular}{|c|c|c|c|c|c|c|c|c|}
\hline Comprimento $(\mathrm{cm})$ & M1 & M2 & M3 & M4 & F1 & F2 & F3 & Total \\
\hline 10 & 0 & $12(16,7)$ & $1(1,5)$ & $1(3,2)$ & 0 & $2(2,8)$ & $1(1,4)$ & $17(3,7)$ \\
\hline 20 & $3(4,4)$ & $16(22,2)$ & 0 & 0 & 0 & $3(4,2)$ & $2(2,8)$ & $24(5,3)$ \\
\hline 30 & $2(2,9)$ & $15(20,8)$ & $3(4,5)$ & $4(12,9)$ & $6(8,1)$ & $9(12,7)$ & $6(8,3)$ & $45(9,9)$ \\
\hline 40 & $4(5,9)$ & $11(15,3)$ & $6(9,1)$ & $10(32,2)$ & $11(14,9)$ & $10(14,1)$ & $11(15,3)$ & $63(13,9)$ \\
\hline 50 & $3(4,4)$ & $12(16,7)$ & $8(12,1)$ & $7(22,6)$ & $11(14,9)$ & $18(25,3)$ & $6(8,3)$ & $65(14,3)$ \\
\hline 60 & $8(11,8)$ & 0 & $20(30,3)$ & $7(22,6)$ & $15(20,3)$ & $17(23,9)$ & $14(19,4)$ & $81(17,8)$ \\
\hline 70 & $33(48,5)$ & $4 \quad(5,6)$ & $16(24,2)$ & $2(6,4)$ & $8(10,8)$ & $7 \quad(9,8)$ & $17(23,6)$ & $87(19,2)$ \\
\hline 80 & $15(22,0)$ & $2(2,8)$ & $12(18,2)$ & 0 & $23(31,0)$ & $5 \quad(7,0)$ & $15(20,8)$ & $72(15,8)$ \\
\hline
\end{tabular}

M2. Quanto às fêmeas, não foi verificada defesa de território, embora F1 apresentasse maior tendência de distribuição para a direção do território de M1. F2 foi observada entre os territórios dos M1 e M2.

Observou-se que M1, M3 e F2 estiveram com maior freqüência na região posterior do aquário e M4 na anterior (Tab. IV). Entretanto, M2 distribuiu-se quase que eqüitativamente entre as duas regiões e F2 e F3 na região anterior do aquário.

$\mathrm{Na}$ análise de agrupamento das amostras combinadas das posições dos peixes no espaço físico (Fig. 1), pode-se observar que M4 se diferenciou dos demais, enquanto M1, M3 e F1 formaram um grupo e M2, F2 e F3, um outro. M4 permaneceu grande parte do tempo no fundo, M1, M3 e F1 no lado direito e na região posterior do aquário e M2, F2 e F3, no lado esquerdo e na região anterior. Aparentemente, M3 era forçado por M1 a manter-se nas posições média e superior da coluna da água, como pode ser observado pelo número de interações sociais (Tab. I).

\section{Comportamento reprodutivo}

O comportamento de corte é sempre realizado pelo macho em relação à fêmea e nunca foi observado entre as fêmeas ou delas com os machos. Sucessivos padrões de comportamento são apresentados quando um macho encontra uma fêmea. Após detecção da parceira existe um período preparatório do macho, verificado por uma extensão prévia das nadadeiras, mudança gradativa da cor vermelha para o azul escuro, quase negro, e posterior fechamento das nadadeiras ímpares. A mudança da coloração inicia-se na cauda e estende-se até a cabeça. A coloração do macho apresenta-se intermediária (azul escuro na cauda e vermelha na cabeça) quando ocorre corte à fêmea, seguido de ataque a um macho em períodos de tempo muito próximos.

Na corte, o macho persegue a fêmea até que ela o siga e

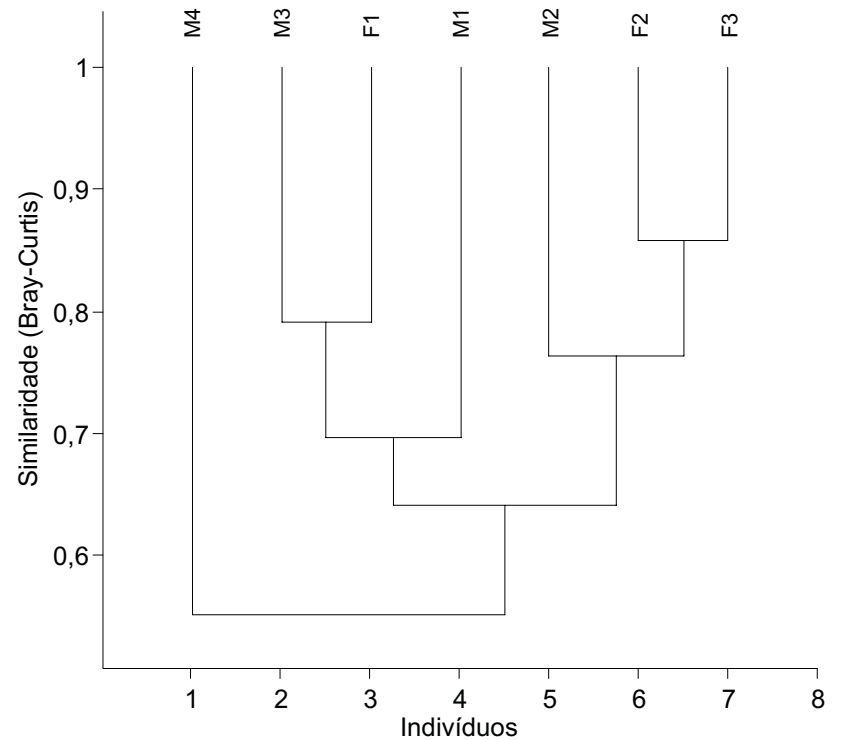

Figura 1. Análise de agrupamento das amostras combinadas das posições dos exemplares de Simpsonichthys boitonei no espaço físico. $M=$ macho, $F$ = fêmea.

só interrompe o processo se houver indiferença (uma reação negativa da fêmea aos estímulos sexuais do macho, do qual ela se afasta). Quando aborda a fêmea, o macho movimenta-se de um lado para outro, passando por cima dela, estremecendo o corpo, geralmente em posição oblíqua de cabeça para baixo, com as nadadeiras anal, caudal e dorsal fechadas. Enquanto é seguido pela fêmea, o macho procura um substrato adequado para a desova, enterrando-se em vários locais diferentes, em

Tabela IV. Freqüência numérica e porcentual (entre parênteses) da distribuição transversal (região anterior e posterior do aquário) de machos (M) e fêmeas (F) de Simpsonichtys boitonei.

\begin{tabular}{lcccccccc}
\hline Região do aquário & M1 & M2 & M3 & M4 & F1 & F2 & F3 & Total \\
\hline Anterior & $16(23,5)$ & $38(52,8)$ & $15(22,7)$ & $19(61,3)$ & $05(6,75)$ & $48(67,6)$ & $48(66,7)$ & $194(41,8)$ \\
Posterior & $52(76,5)$ & $34(47,2)$ & $51(77,3)$ & $12(38,7)$ & $69(93,2)$ & $23(32,4)$ & $24(33,3)$ & $270(58,2)$ \\
\hline
\end{tabular}


um ângulo que varia de 60 a $75^{\circ}$. Por fim, a fêmea penetra no substrato ao lado do macho. Pode ocorrer penetração parcial ou total, mas o macho sempre pressiona a fêmea contra o substrato com o seu corpo. Essa compressão pode se realizar tanto pelo lado direito quanto esquerdo do macho. Eles permanecem nesta posição por alguns segundos, após o qual o macho emerge, enquanto a fêmea permanece enterrada, saindo do substrato após um período de 5 a 30 segundos. O macho mantém-se nas proximidades, reiniciando a corte logo que ela emerge do substrato.

\section{DISCUSSÃO}

Diferentes ocupações dos estratos possibilitam a convivência de espécies simpátricas em um ambiente tão limitado em espaço físico como uma poça temporária. BAstos (1984) notou que $S$. boitonei ocupava o extrato inferior da coluna d'água, comportamento corroborado neste trabalho, ao contrário de outro Rivulidae, Rivulus pictus Costa, 1989, que ocupava o extrato superior. Juvenis de Astyanax aff. scabripinnis (Jenyns, 1842) foram observados no ambiente, durante nossas coletas, geralmente no meio da coluna da água.

O comportamento dos machos permanecerem próximos ao substrato e no seu território, enquanto as fêmeas exploram outras partes da coluna d'água, pode explicar as diferenças quantitativas na ingestão de micro-crustáceos observadas por SHIBATTA \& Rocha (2001). As fêmeas, por percorrerem uma área maior, têm a possibilidade de ingerir grande número desses organismos. Além disso, ao mesmo tempo em que se alimentam, encontram parceiros para a reprodução.

Os constituintes básicos das interações sociais de Simpsonichthys boitonei tiveram caráter reprodutivo e agonístico, não se observando outras formas de relacionamentos. Essas interações foram estereotipadas e realizadas em várias etapas, que podemos reconhecer como padrões fixos de ação que caracterizam a espécie. Os cinco estágios do comportamento reprodutivo observados por Belote \& Costa (2003) em Cynolebias albipunctatus Costa \& Brasil, 1991 (apresentações para corte, convite à submersão, submersão, desova/fertilização e emersão) puderam ser observados em $S$. boitonei. Dos 31 padrões comportamentais descritos para o gênero Cynolebias Steindachner, 1876 (VAz-Ferreira \& Sierra 1973; atualmente as espécies analisadas por esses autores estão alocadas nos gêneros Austrolebias Costa, 1998 e Cynopoecilus Regan, 1912), apenas a introdução do focinho da fêmea no ângulo axilar do macho ("adosamiento") e subordinação da fêmea pelas nadadeiras dorsal e anal do macho ("sujeción de la hembra por aleta dorsal y anal del macho") não foram observados em S. boitonei. Com exceção desses comportamentos, podemos supor que são as pequenas diferenças quantitativas de cada etapa do comportamento que diferenciam $S$. boitonei das outras espécies. Provavelmente essas pequenas variações interespecíficas sejam frutos da evolução do comportamento a partir de um modelo ancestral, comum a diferentes gêneros da subfamília Cynolebiatinae.
O emparelhamento e os movimentos da nadadeira caudal dos machos servem para medir forças entre os indivíduos, com a estimulação dos neuromastos dos flancos e da cabeça evitando, muitas vezes, o contato direto dos oponentes (Tinbergen 1981). Para evitar confrontos entre macho e fêmea, a coloração diferenciada certamente é um fator importante. A intensificação da coloração avermelhada esteve relacionada à agressão, enquanto a mudança para o azul escuro serviu como sinal visual para demonstrar receptividade do macho à fêmea. Neste trabalho, a alteração no padrão de colorido do macho durante a corte corrobora o observado por BELOTE \& CosTA (2002), que consideraram esse comportamento como uma característica comum a 10 espécies de Simpsonichthys. Outro caráter observado nesse estudo, e que foi considerado sinapomórfico para o grupo constituído por $S$. parallelus, Simpsonichthys sp., $S$. boitonei, $S$. santanae e $S$. zonatus (Belote \& Costa 2002), é o fechamento das nadadeiras ímpares durante a corte.

Assim como foi observado em $S$. boitonei, as posições de apaziguamento em outras espécies de Cynolebiatinae são demonstradas principalmente pelos machos de menor tamanho, que são perseguidos por machos ou fêmeas maiores e, ao contrário de $S$. boitonei, machos de algumas espécies ainda apresentam comportamento pseudo-feminino (VAz-Ferreira \& Sierra 1973). A fuga pela simples presença do oponente, como foi observado, não significa que a ameaça não tenha ocorrido, pois podem ocorrer comportamentos mais sutis, como o observado por BeLote \& Costa (2003) durante a corte de Cynolebias albipunctatus, em que os machos permanecem sem realizar grandes movimentos do corpo em frente à fêmea, mas com pequenos movimentos da cabeça, produzindo estalos. Além disso, o macho de maior tamanho perdendo território para aquele macho na segunda posição hierárquica permite uma reflexão sobre a ordem de dominância relacionada com o tamanho e/ou com a idade, o que poderia ser objeto para futuros estudos com a espécie.

O fato de $S$. boitonei penetrar totalmente ou parcialmente no substrato para a desova, pode estar relacionado com a forma de seu corpo, intermediário entre o alto e o alongado. Segundo VAz-Ferreira \& Sierra (1973) as espécies de corpo esguio freqüentemente penetram totalmente no substrato, mas nas espécies com maior altura do corpo, a penetração é parcial. Peters \& Seegers (1978) apresentam uma seqüência de fotos da desova de $S$. boitonei em que se observa um casal apenas parcialmente imerso no substrato.

As desovas ocorridas a temperaturas de 23 e $24^{\circ} \mathrm{C}$ justifica-se pelo fato da espécie ser mais ativa a temperaturas entre 22 a $25^{\circ} \mathrm{C}$, tornando-se menos ativa a temperaturas superiores a $28^{\circ} \mathrm{C}$, como observado por Kadlec (1986). Segundo Couture (1988) ela também se torna letárgica em temperaturas inferiores a $18^{\circ} \mathrm{C}$.

Apesar de Romie (1979) não considerar que os peixes anuais sejam territorialistas, os machos observados de $S$. boitonei apresentaram defesa de uma determinada área e, por isso, podem ser considerados territorialistas. Em uma das poucas obser-

Revista Brasileira de Zoologia 23 (2): 375-380, junho 2006 
vações no ambiente natural, BASTOS (1984) notou dois machos de $S$. boitonei em uma poça de água, onde o maior perseguia insistentemente o menor, dilacerando-lhe as nadadeiras. Entretanto, os exemplares deste trabalho, quando coletados no Brejo da Cerca, apresentavam suas nadadeiras integras, demonstrando que os contatos agressivos eram menos freqüentes. Ou seja, a densidade populacional é um fator relevante e que determina a freqüência das interações sociais. No brejo estacional, a área de ocupação dos peixes tende a diminuir em decorrência da seca e, como conseqüência, a densidade populacional deve aumentar e o alimento disponível diminuir. Possivelmente, até que o brejo esteja completamente seco, apenas aqueles adultos maiores e que não estejam senis é que conseguirão manter um território e reproduzir, como ocorre com outros animais (MANNING 1977). Provavelmente, devido à capacidade de suporte do ambiente, determinado principalmente pela disponibilidade de alimentos e presença de locais de abrigo e procriação, a territorialidade pode ter um significado adaptativo que restringe e controla o tamanho da população, conforme já havia preconizado WynneEdwards (apud MANNING 1977) para animais territorialistas.

\section{AGRADECIMENTOS}

Meus sinceros agradecimentos ao Dr. Antônio José Andrade Rocha pela orientação inicial do trabalho na Universidade de Brasília. Ao Dr. Mauro Ribeiro da RECOR, pela autorização de coleta. Ao Dr. Ivan Sazima, pela leitura crítica da primeira versão do manuscrito. Ao CNPq pela concessão de bolsa IC (processo 102177/87).

\section{REFERÊNCIAS}

ALtMANN, J. 1974. Observational study of behavior: sampling methods. Behaviour, Noordbroek, 49: 227-267.

Bastos, E.K. 1984. Cynolebias boitonei, in Zentralbrasilien beobachtet. Das Aquarium, Bornheim, 18 (177): 119-123.

Belote, D.F. \& W.J.E.M. Costa. 2002. Reproductive behavior patterns in the neotropical annual fish genus Simpsonichthys Carvalho, 1959 (Cyprinodontiformes, Rivulidae): Description and phylogenetic implications. Boletim do Museu Nacional, Rio de Janeiro, 489: 1-10.

Belote, D.F. \& W.J.E.M. Costa. 2003. Comportamento reprodutivo do peixe anual brasileiro Cynolebias albipunctatus Costa \& Brasil, 1991 (Teleostei, Cyprinodontiformes, Rivulidae): um novo relato de produção de som em peixes. Arquivos do Museu Nacional, Rio de Janeiro, 61 (4): 241-244.

Carvalho, A.L. 1959. Novo gênero e nova espécie de peixe anu- al de Brasília, com uma nota sobre os peixes anuais da baixada fluminense, Brasil. Boletim do Museu Nacional, Rio de Janeiro, 201: 1-10.

Costa, W.J.E.M. 1995. Pearl killifishes: the Cynolebiatinae. Neptune City, TFH Publications, 128p.

CostA, W.J.E.M. 2002. Peixes anuais brasileiros: diversidade e conservação. Curitiba, Editora da UFPR, 238p.

Couture, G. 1988. Cynolebias boitonei (de Carvalho) (I). Fiche no 334. Revue française d'Aquariologie, Saint-Nicolas-dePort, (Supl. 2/88): 1-2.

Couture, G. 1989. Cynolebias boitonei (de Carvalho) (II). Fiche no 337. Revue française d'Aquariologie, Saint-Nicolas-dePort, (Supl. 3/88): 1-2.

Dathier, V.G. \& E. Stellar. 1973. Comportamento animal. São Paulo, Editora Edgard Blücher, Editora da Universidade de São Paulo, 151p.

KAdLEC, J. 1986. The lyre-fined pearlfish: Cynolebias boitonei. Tropical Fish Hobbyist, Neptune City, 35 (1): 70-73.

MANning, A. 1977. Introdução ao comportamento animal. Rio de Janeiro, Livros Técnicos e Científicos Editora, 354p.

Hammer, Ø., D.A.T. Harper \& P.D. Ryan. 2001. PAST: Paleontological Statistics Software Package for Education and Data Analysis. Palaeontologia Electronica 4 (1): 1-9. Available in the World Wide Web at: http://palaeo-electronica.org [accessed in 13.IV.2006]

Peters, F. \& L. Seegers. 1978. Ein fisch ohne Bauchflossen Cynolebias boitonei. Aquarien Magazin, Berlin, 1218: 390395.

Romie, B. 1979. Some personal observation on killifish behavior. Journal of American Killifish Association, New York, 112 (1): 24-26.

Shibatta, O.A. \& J.C. Garavello. 1992. Descrição de uma nova espécie do gênero Cynolebias Steindachner do Brasil Central (Pisces: Cyprinodontiformes). Comunicações do Museu de Ciências da PUCRS, Série Zoologia, Porto Alegre, 5 (11): 179-195.

Shibatta, O.A. \& A.J.A. Rocha. 2001. Alimentação em machos e fêmeas do pirá-brasília, Simpsonichthys boitonei Carvalho (Cyprinodontiformes, Rivulidae). Revista Brasileira de Zoologia, Curitiba, 18 (2): 381-385.

Tinbergen, N. 1981. Comportamento animal. Rio de Janeiro, Livraria José Olympio Editora, 199p.

Vaz-Ferreira, R. \& B. Sierra. 1973. Caracteres etológicos genéricos y específicos en los peces del genero Cynolebias Steindachner, 1876. Boletín de la Sociedad Zoológica del Uruguay, Montevideo, 2: 22-35.

Recebido em 05.VII.2005; aceito em 17.IV.2006. 